\title{
Epac-mediated relaxation in murine basilar arteries depends on membrane permeability of cyclic nucleotide analogues and endothelial aging
}

\author{
Johannes Welter ${ }^{1}$, Gabriele Pfitzer ${ }^{1}$, Olaf Grisk ${ }^{2,3}$, Jürgen Hescheler ${ }^{4}$ and Lubomir T. Lubomirov ${ }^{1}$ \\ ${ }^{1}$ Institute of Vegetative Physiology, Center of Physiology, University of Cologne, Cologne, Germany \\ ${ }^{2}$ Institute of Physiology, University of Greifswald, Greifswald, Germany \\ ${ }^{3}$ Department of Physiology, Brandenburg Medical School Theodor Fontane, Brandenburg, Germany \\ ${ }^{4}$ Institute of Neurophysiology, Center of Physiology, University of Cologne, Cologne, Germany
}

\begin{abstract}
Cerebral blood supply is finely tuned by regulatory mechanisms depending on vessel caliber the disruption of which contributes to the development of diseases such as vascular dementia, Alzheimer's and Parkinson 's diseases. This study scopes whether cAMP-mimetic-ligands relax young and aged murine cerebral arteries, whether this relates to the activation of PKA or Epac signaling pathways and is changed with advanced age. The hormone Urocortin-1 relaxed submaximally contracted young and old basilar arteries with a similar $\mathrm{pD}_{2}$ and $\mathrm{D}_{\mathrm{MAX}}(\sim-8.5$ and $\sim 90 \%$ in both groups). In permeabilized arteries, PKA activation by 6-Bnz-cAMP or Epac activation by 8-pCPT-2'$\mathrm{O}$-Me-cAMP also induced relaxation with $\mathrm{pD}_{2}$ of $-6.3 v s$. -5.8 in old for PKA-ligands, and -4.4 and -4.0 in old for Epac-ligands. Furthermore, aging significantly increased submaximal $\mathrm{Ca}^{2+}$-induced force. The effect of 8-pCPT-2'-O-Me-cAMP on intact arteries was attenuated by aging or nitric oxide synthase inhibition. No relaxing effect in both age-groups was observed after treatment with PKAactivator, Sp-6-Phe-cAMPS. In conclusion, our results suggest that in intact basilar arteries relaxation induced by cAMP-mimetics refers only to the activation of Epac and is impaired by smooth muscle and endothelial aging. The study presents an interesting option allowing therapeutic discrimination between both pathways, possibly for the exclusive activation of Epac in brain circulatory system.
\end{abstract}

Key words: Vascular tone - Aging - Basilar artery - PKA- and Epac-ligands - cAMP-membrane permeability

Abbreviations: 6-Bnz-cAMP, $\mathrm{N}^{6}$-Benzoyladenosine-3', 5'-cyclic monophosphorothioate Sp-isomer sodium salt; 8-pCPT-2'-O-Me-cAMP, 8-(4-Chlorophenylthio)-2'-O-methyladenosine-3', 5'-cyclic monophosphate; Epac, echange-protein-directly-activated by cAMP; PKA, proteinkinase A; Sp6-Phe-cAMPS, $\mathrm{N}^{6}$-Phenyladenosine-3', 5'-cyclic monophosphorothioate $\mathrm{Sp}$-isomer, sodium salt.

\section{Introduction}

\section{Clinical background}

The cerebral circulation possesses a variety of finely tuned regulatory mechanisms that ensure adequate blood supply

Correspondence to: Lubomir T. Lubomirov, Institute of Vegetative Physiology, University of Cologne, Robert Koch Str. 39, 50931 Cologne, Germany

E-mail: lubomir.lubomirov@uni-koeln.de to the brain. A disruption of these mechanisms leads to impairment in brain metabolism and thus to brain functional disorders (Iadecola et al. 2009). Aging causes changes throughout all components of the neurovascular unit i.e. endothelium, smooth muscle and perivascular cells such as neurons or astrocytes (Lubomirov et al. 2017). The neurovascular unit participates in cerebrovascular control by releasing vasoactive agents such as nitric oxide, prostaglandins or endothelin. Furthermore, structural brain damage caused by ischemic events and cerebral mal-perfusion contributes to the development of incurable chronic diseases such as 
vascular dementia, Alzheimer's and Parkinson's diseases (Yang et al. 2017). Usually, these pathological aberrations are tightly related to an improper cerebral blood flow distribution, which by itself depends on contractile activity of the cerebral vasculature, i.e. cerebrovascular tone.

Cerebrovascular tone is determined by the contractile state of the medial smooth muscle layer. A rise in pressure or vasoconstrictor agonist stimulation triggers $\mathrm{Ca}^{2+}$-entry into the vascular smooth muscle cytosol via plasmalemmal $\mathrm{Ca}^{2+}$. channels or $\mathrm{Ca}^{2+}$-release from intracellular stores (Mufti et al. 2010). This leads to a reversible phosphorylation of the $20 \mathrm{kDa}$ regulatory light chains of myosin $\left(\mathrm{MLC}_{20}\right)$, causing an interaction between actin and myosin, cross-bridge cycling and force generation (Pfitzer 2001). The activity of the contractile apparatus depends on $\mathrm{Ca}^{2+} /$ calmodulin (CaM)-activated myosin light chain kinase (MLCK), an enzyme catalyzing $\mathrm{MLC}_{20}$-phosphorylation, and the myosin light chain phosphatase (MLCP) responsible for dephosphorylation of the $\mathrm{MLC}_{20}$. Typically, all agonists triggering vasoconstriction or vasorelaxation affect these two enzymes and thus change the ratio of their activities (Somlyo and Somlyo 2003).

Historically, starting from the early 1970's, the majority of the investigations were focused on the regulation of MLCK based on the presumption that when smooth muscle tone generation is preceded by a rise in intracellular $\mathrm{Ca}^{2+}$, the latter leading to an increase in MLCK activity, the direct regulation of the MLCK activity has to be of main importance for vascular tone maintenance (Walsh and Cole 2013). However, the notion that MLCP is regulated was found by the laboratory of Somlyo a decade later. It was recognized that MLCP is permanently active and sets the degree of $\mathrm{MLC}_{20}$ phosphorylation and, hence, of smooth muscle tone (reviewed in Somlyo and Somlyo 2003). MLCP is a type Serine/Threonine phosphatase consisting of tree subunits: the catalytic subunit, PP1c, the $115 \mathrm{kDa}$ regulatory (myosin phosphatase targeting) subunit (MYPT1) and a small, $21 \mathrm{kDa}$ subunit, with an unknown function (Walsh and Cole 2013). It is now well known that the catalytic activity of the enzyme is modulated by inhibitory phosphorylation of the targeting subunit MYPT1 (Feng et al. 1999a). MYPT1 contains several phosphorylation sites. Phosphorylation of Threonine 696 (T696) and Threonine 853 (T853) causes inhibition of MLCP activity (Feng et al. 1999b; Khromov et al. 2009). The phosphorylation degree of these sites is primarily regulated by the activity of Rho/ Rho-kinase pathway (Rho/ROK) as in smooth muscle and non-muscle cells they are significantly phosphorylated under resting conditions in a ROK-independent manner (Puetz et al. 2009).

It is well established that vasorelaxation of cerebral vessels occurs in two different manners $(i)$ passive by removal of extracellular vasoconstricting stimuli lowering the activity of the $\mathrm{Ca}^{2+} / \mathrm{CaM} / \mathrm{MLCK}$ complex or (ii) active via increasing the activity of MLCP. In the context of vascular tone maintenance, the active relaxation is usually due to a rise in the intracellular cyclic nucleotide concentration which in turn either lowers intracellular $\mathrm{Ca}^{2+}$ or decreases the calcium-sensitivity of the contractile machinery, reviewed in (Pfitzer 2001; Somlyo and Somlyo 2003). Over the past decades a number of seminal studies provided evidence that $\mathrm{cGMP}$ and $\mathrm{cAMP}$ are key regulators responsible for the desensitization of vasoconstrictor stimuli in vasculature (Pfitzer et al. 1984,1985). It is now well appreciated that these biologically active second messengers are the central element of the so-called active relaxation. Cyclic nucleotides are able to reduce or even in some cases to completely block the contractility independently of the stimulation grade of the smooth muscle cells (Puetz et al. 2009). Organic nitrates were the first large pharmacological group medicines investigated as compounds able to induce cGMP-dependent $\mathrm{Ca}^{2+}$-desensitization (Etter et al. 2001; Kitazawa et al. 2003). Furthermore, identification of physiologically active peptides, the so-called urocortins (UCN-1, -2, and -3) focused the attention of many investigators to search for therapeutics targeting the cAMP pathway (Emeto et al. 2011).

Cyclic adenosine monophosphate (cAMP) is a cyclic nucleotide discovered more than half a century ago and serves as a second messenger coordinating multiple intracellular processes, including energy expenditure, gene transcription, immune responses, cell-proliferation and survival, platelet aggregation, smooth muscle tone, memory formation etc. (Poppinga et al. 2014; Brescia and Zaccolo 2016). It is produced by perimembrane conversion of ATP into cAMP by the enzyme adenylate cyclase activated by various G-protein-coupled receptors that bind neurotransmitters, hormones or drugs (Parnell et al. 2015). The intracellular cAMP concentration also depends on specific phosphodiesterases which via hydrolysis convert cAMP into 5'-cAMP and thus terminate the activity of the second messenger or A-kinase anchored protein responsible for the intracellular localization and compartmentalization of the cAMP pools (Lezoualc'h et al. 2016). Physiological effects of cAMP are related to the activation of various intracellular effector-proteins containing specific cyclic nucleotide binding domains (CNBD) (Metrich et al. 2010). Until the end of last century, these effects were generally attributed to the activation of either protein kinase A (PKA) or cyclic nucleotide-gated ion-channels (CNGCs). Recently, two independent research groups identified a novel cAMP-effector containing CNBD, so called Exchange-protein-directlyactivated by cAMP (Epac) (Lezoualc'h et al. 2016). Epac's are a family of multi-domain proteins expressed in two main isoforms, Epac1 and Epac2, which serve as guanine nucleotide exchange factors for the small GTPase proteins Rap1 and Rap2 (Ramos and Antonetti 2017). Independent 
of some specificity in localization both Epac1 and Epac2 are involved in various cell functions like cell adhesion, actin polymerization, smooth muscle contraction, endothelial permeability and exocytosis (Fukuhara et al. 2005; Kooistra et al. 2005; Zieba et al. 2011; Alenkvist et al. 2017), reviewed in Ramos and Antonetti (2017). Moreover, several reports from model- or in-vivo experimental systems revealed a significant contribution of Epac's to pathological states (Parnell et al. 2015; Lezoualc'h et al. 2016; Ramos and Antonetti 2017), suggesting that Epac targeting might represent an interesting therapeutic option.

It was an important discovery in the field of cAMP biochemistry/pharmacology that the addition of the methyl group on 2' position on ribose ring dramatically reduced the ability of the cAMP-derivates to activate PKA (Metrich et al. 2010). Unlike for binding to PKA, this hydroxyl group is not required for Epac activation, allowing synthesis of specific pharmacological ligands enabling to distinguish between PKA and Epac-mediated effects. These novel substances have a 100 -fold higher affinity to Epac than to other cAMP target proteins (Lezoualc'h et al. 2016) and allow to test Epacligands as tools for treatment of various diseases, including cardiovascular disorders (Parnell et al. 2015). However, in vivo applications have been limited due to the insufficient cell membrane permeability of cAMP-analogues. Moreover, adverse effects such as development of cardiac arrhythmia and fibrosis as well as certain off-target effects, like PDE activation were observed, reviewed in Parnell et al. (2015). Despite the scientific progress in the field of intracellular Epac-targets, the effects of Epac-ligands on the vasculature, especially on cerebral arteries remains still uncertain. Recently, we have shown that unlike cGMP, cAMP seems to be a more general system for vasorelaxation (Lubomirov et al. 2018). We have found that compared to cGMP-induced relaxations, those induced by CAMP-mimetics is to lesser extend dependent on localization of the vascular bed, i. e. systemic versus brain arteries (Lubomirov et al. 2018).

The present study aims to explore whether Epac- or PKA-mimetic-ligands relax murine cerebral arteries. The study also tests whether the cAMP-related vasorelaxation in murine basilar arteries (representative for posterior brain circulation) relates to the activation of PKA or Epac and is impaired by advanced age and senescence. To distinguish between the cAMP-pathways and aging related differences we tested compounds that specifically activate PKA and Epac on young mature and old aged basilar arteries. Keeping in mind that Epac could increase NO release from vascular endothelium (Chrzanowska-Wodnicka 2017) we also tested the effects of the compounds under pan-inhibition of NOS. To further characterize the dependence of relaxing effect on compound concentration we also tested the relaxation induced by these cAMP analogues in Staphylococcus aureus a-toxin permeabilized vessels from both age groups.

\section{Materials and Methods}

\section{Animals}

$\mathrm{C} 57 \mathrm{BL} / 6 \mathrm{~N}$ mice, used in this project were kept in the animal facility of Medical Faculty of the University of Cologne in compliance with the recommendations of the European Union $(2007 / 526 / E G)$. The animal procedures were approved by the State Office for Nature, Environment and Customer Protection North Rhine Westphalia: AZ 84-02.05.50.15.029) and were carried out in accordance with the guidelines of the European Commission (Directive 2010/63/EU) and the German Animal Welfare Act.

\section{Preparation and mounting of basilar arteries}

At the time of specimen collection, the mice used for the current project were between 8-12 weeks (young, mature mice) or $>18$ months old (aged mice). The animals were anesthetized with isoflurane and sacrificed by decapitation. Subsequently, the skull was quickly opened, the brain removed and transferred in a Petri-dish filled with ice cold HEPES-buffered low $\mathrm{Ca}^{2+}$ physiological saline solution (low- $\mathrm{Ca}^{2+} \mathrm{HPSS}$, see solutions) and pin-fixed. The basilar artery was dissected, divided into two approximately equal pieces of $1.8-2 \mathrm{~mm}$ length and the preparations were left in the same solution for $10 \mathrm{~min}$. Thereafter arterial rings were mounted on $25 \mu \mathrm{m}$ tungsten wires in a wire-myograph (model 610A, Danish Myotechnology, Aarhus, Denmark) and left for another $10 \mathrm{~min}$ in the same solution. Then, the low-Ca ${ }^{2+} \mathrm{HPSS}$ was replaced by $\mathrm{HCO}_{3}{ }^{-}$/ $\mathrm{CO}_{2}$ buffered PSS (see solutions) and the temperature was increased to $37^{\circ} \mathrm{C}$. $\mathrm{pH}$ was continuously kept at 7.4 during the experiment. Thereafter, the ring preparations were stretched stepwise to $\mathrm{IC}_{90}$ (internal circumference corresponding to $90 \%$ of the internal circumference reached at a wall tension corresponding to a transmural pressure of $100 \mathrm{mmHg}$ ) as described previously (Mulvany and Halpern 1977; Lubomirov et al. 2018). Then, the vessels were allowed to equilibrate for 20 min before subjecting them to the experimental protocols.

For mounting and equilibration of the $\alpha$-toxin permeabilized basilar arteries see the protocol described below in the section "Vasorelaxation of submaximally precontracted a-toxin permeabilized basilar arteries".

\section{Experimental protocols}

Vasorelaxation of submaximally precontracted intact basilar arteries

Isolation of the arteries and pre-stretching were carried out by the steps described above. After 20 min equilibration, a maximum contraction was induced by application of $3 \times 10^{-6}$ $\mathrm{mol} / \mathrm{l}$ of stable thromboxane $\mathrm{A}_{2}$ receptor agonist, U46619. 
Then the arteries were washed out four times with PSS and left to recover tone for 10-15 $\mathrm{min}$. Thereafter, the vessels were incubated for $20 \mathrm{~min}$ with $10^{-4} \mathrm{~mol} / \mathrm{l} \mathrm{N}_{\omega}$-Nitro-L-arginine methyl ester hydrochloride (L-NAME) and submaximally contracted by application of $2 \times 10^{-7} \mathrm{~mol} / 1 \mathrm{U} 46619$. After 20 min of stimulation and stabilization of submaximal tone, increasing concentrations of urocortin-1 (UCN-1; $10^{-10}-10^{-7}$ $\mathrm{mol} / \mathrm{l})$, the PKA activators 6-Bnz-cAMP $\left(10^{-6}-10^{-4} \mathrm{~mol} / \mathrm{l}\right)$ or Sp-6-Phe-cAMPS $\left(3 \times 10^{-5}-3 \times 10^{-4} \mathrm{~mol} / \mathrm{l}\right)$ or the Epac activator 8-pCPT-2'-O-Me-cAMP $\left(10^{-4}-3 \times 10^{-4} \mathrm{~mol} / \mathrm{l}\right)$ were added to the organ bath in 10 minute time intervals. At the end of the experiment, the arteries were again washed four times and incubated with $2 \times 10^{-3} \mathrm{~mol} / \mathrm{l}$ EGTA in PSS to obtain the basal vascular tone under $\mathrm{Ca}^{2+}$-free conditions.

\section{Vasorelaxation of submaximally precontracted $\alpha$-toxin permeabilized basilar arteries}

Arteries, isolated as described above, were left at room temperature for $10 \mathrm{~min}$ in a $1.5 \mathrm{ml}$ reaction tube with low-Ca ${ }^{2+}$ HPSS. Then, the low-Ca ${ }^{2+}$ HPSS was exchanged by $\mathrm{Ca}^{2+}$-free HPSS ( $2 \mathrm{mmol} / \mathrm{l}$ EGTA) and after $10 \mathrm{~min}$ the vessels were placed in another tube with $50 \mu$ relaxation solution with a pCa of $>8$ (see solutions) for additional $15 \mathrm{~min}$. The arterial segments were then incubated for $30 \mathrm{~min}$ in $50 \mu \mathrm{l}$ relaxation solution with $400 \mathrm{U}$ Staphylococcus aureus $\alpha$-toxin. This exotoxin forms $2-3 \mathrm{~nm}$ pores in the cell membrane, allowing unrestricted diffusion between intracellular and extracellular spaces of low molecular weight molecules $(<1 \mathrm{kDa}$ such as ATP, cyclic nucleotides or inorganic ions such as $\mathrm{Ca}^{2+}, \mathrm{Mg}^{2+}$, $\mathrm{K}^{+}, \mathrm{Na}^{+}$, etc.) while keeping the intracellular signal cascades intact (Pfitzer 2001). Thereafter, the permeabilized arterial rings were mounted on $25 \mu \mathrm{m}$ tungsten wires in a wiremyograph (model 610A, DMT myotechnology, Denmark) in relaxing solution $(\mathrm{pCa}>8)$. The ring preparations were then stretched stepwise to $\mathrm{IC}_{90}$ as described above. The vessels were allowed to equilibrate for $20 \mathrm{~min}$ before subjecting them to the experimental protocols. To deplete $\mathrm{Ca}^{2+}$-stores, the preparations were incubated during the equilibrating period with $10 \mu \mathrm{mol} / \mathrm{l}$ A23187. Thereafter, a submaximal contraction was elicited by replacement of pCa $>8$-solution with contraction solution at $\mathrm{pCa}$ 6.21. After $15 \mathrm{~min}$, vascular tone reached a plateau. Then, the cyclic nucleotides 6-Bnz-cAMP (conc. range $10^{-7}-10^{-4} \mathrm{~mol} / \mathrm{l}$ ) or 8-pCPT-2'O-Me-cAMP (conc. range $3 \times 10^{-6}-3 \times 10^{-4} \mathrm{~mol} / \mathrm{l}$ ) were cumulatively added (10 min incubation at each concentration; dissolved in pCa 6.21 solution). Once maximal relaxation by the cyclic nucleotides had reached a plateau, the preparations were maximally stimulated by a contracting solution with pCa 4.3 and at the end of the experiment relaxed in solution with $\mathrm{pCa}>8$. The extent of nucleotide-induced relaxation was expressed in percent of the force elicited by pCa 6.21 prior to incubation with the cyclic nucleotides analogues. The experiments were carried out at room temperature $\left(23^{\circ} \mathrm{C}\right)$ and all substances were added directly to the organ bath of the myograph.

\section{Solutions for wire myography}

\section{Intact preparations}

Low-Ca ${ }^{2+}$ HPSS (in mmol/l): $118 \mathrm{NaCl}, 5 \mathrm{KCl}, 1.2 \mathrm{NaH}_{2} \mathrm{PO}_{4}$, $1.2 \mathrm{MgCl}_{2}, 0.16 \mathrm{CaCl}_{2}, 10$ Glucose, and $24 \mathrm{HEPES}, \mathrm{pH} 7.4$ at room temperature. $\mathrm{HCO}_{3}{ }^{-} / \mathrm{CO}_{2}$ buffered PSS (in $\mathrm{mmol} / \mathrm{l}$ ): $119 \mathrm{NaCl}, 4.7 \mathrm{KCl}, 1.18 \mathrm{KH}_{2} \mathrm{PO}_{4}, 1.17 \mathrm{MgSO}_{4}, 1.6 \mathrm{CaCl}_{2}$, 5.5 glucose, $25 \mathrm{NaHCO}_{3}, 0.03 \mathrm{EGTA}, \mathrm{pH} 7.4$ at $37^{\circ} \mathrm{C}$, equilibrated with carbogen $\left(95 \% \mathrm{O}_{2}, 5 \% \mathrm{CO}_{2}\right)$.

\section{Permeabilized preparations}

Relaxing solution $\left(\mathrm{pCa}=-\log _{10}\left[\mathrm{Ca}^{2+}\right] \geq 8\right)$ contained in mmol/l: 20 imidazole, $7.5 \mathrm{Na}_{2} \mathrm{ATP}, 10$ EGTA, 10 $\left[\mathrm{CH}_{3} \mathrm{COO}\right]_{2} \mathrm{Mg}, 10$ creatine phosphate, 31.25 potassium methanesulfonate, $5 \mathrm{NaN}_{3}, 0.01 \mathrm{GTP}, 0.001$ leupeptin, 2 DTT; $\mathrm{pH}$ of 7.00 was adjusted with $\mathrm{CaCl}_{2}$-free $\mathrm{KOH}$. Contraction solution ( $\mathrm{pCa} 4.3$ ) had the same composition as the relaxing solution except that it contained $10 \mathrm{mmol} / \mathrm{C} \mathrm{CaCl}_{2}$. The $\mathrm{pCa}$ 6.1 solution was obtained by mixing relaxing and contracting solutions in the appropriate ratio (Wirth et al. 2003). The ionic strength of the relaxing and contracting solutions was adjusted with potassium methanesulfonate to $150 \mathrm{mmol} / \mathrm{l}$.

\section{Statistical analysis}

Statistical comparisons were performed by two-way ANOVA, followed by Sidak's test for multiple comparisons; $p \leq 0.05$ was taken to indicate statistical significance. Data are represented as mean \pm standard error of mean as $n$ is the number of individual experiments, which also equals the animal number. $\mathrm{pD}_{2}$ values were obtained from the sigmoidal curve fitting of individual concentration-response relationships.

\section{Results}

UCN-1 mediated relaxation in intact basilar arteries from young and aged mice

We first compared the ability of UCN-1 to dilate submaximally contracted young and old basilar arteries. The effect of this hormone has been shown to be mediated by the increase in intracellular cAMP concentration (Vaughan et al. 1995). To eliminate possible UCN-1 mediated endothelial NO-release as described for coronary and mesenteric vasculature (Huang et al. 2002; Chen et al. 2005), the preparations were incubated with $10^{-4} \mathrm{~mol} / \mathrm{l}$ L-NAME. 

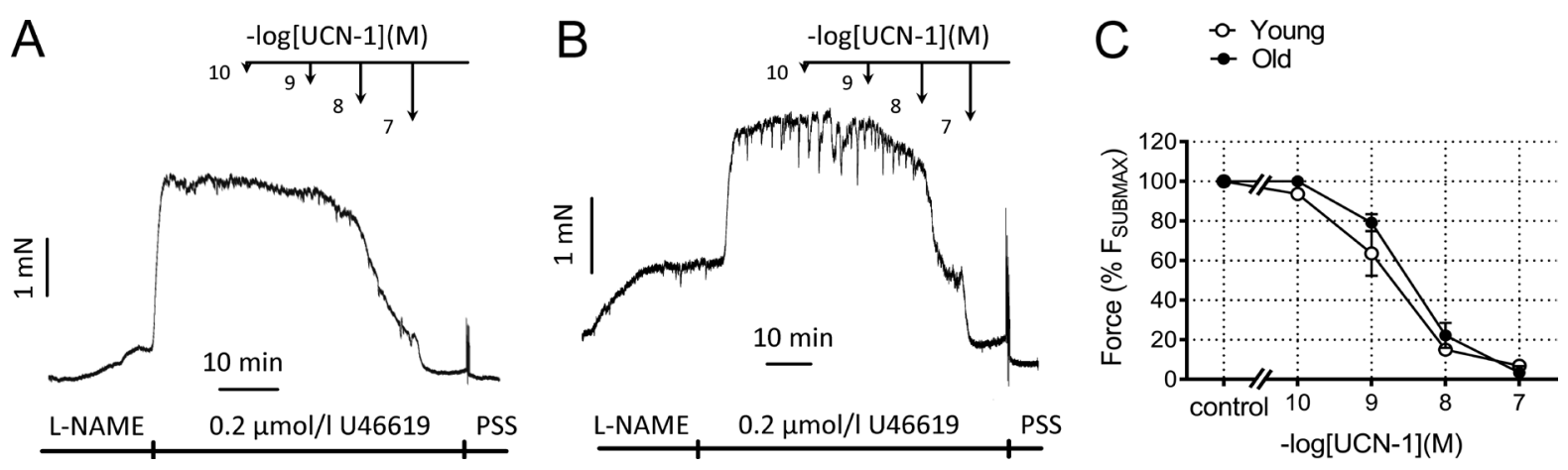

Figure 1. UCN-1-induced relaxation in intact basilar arteries by UCN-1. Original force tracings (A, B) and summarized data (C) representing concentration-dependent relaxation of UCN-1 of submaximally preconstricted $\left(2 \times 10^{-7} \mathrm{~mol} / \mathrm{l} \mathrm{U} 46619\right)$ intact basilar arteries from young and old animals ( $n=5$ young $(\mathrm{A}, \mathrm{C})$ and 4 old $(\mathrm{B}, \mathrm{C})$ basilar arteries). UCN-1 was applied cumulatively in the concentration range $10^{-10}-10^{-7} \mathrm{~mol} / \mathrm{l}$. The values of relaxation were calculated in $\%$ force from FSUBMAX, which represents the contractile force achieved by $2 \times 10^{-7} \mathrm{~mol} / \mathrm{l} \mathrm{U} 46619$ prior to application of UCN-1, accepted as $100 \%$.

The submaximal force developed by application of $2 \times 10^{-7}$ $\mathrm{U} 46619$ was $58.5 \pm 8.8 \%$ of the maximum force $\left(\mathrm{F}_{\max }=\right.$ $3.4 \pm 0.9 \mathrm{mN})$ in the young arteries, and $65.0 \pm 10.1 \%$ of $\mathrm{F}_{\max }\left(\mathrm{F}_{\max }=2.1 \pm 0.5 \mathrm{mN}\right)$ in the old arteries $(p>0.05)$. $\mathrm{UCN}-1$ added on the plateau of contraction relaxed the preparations with a $\mathrm{pD}_{2}$ of $-8.8 \pm 0.2$ in young and -8.5 \pm 0.1 in old arteries. In both experimental groups UCN-1 almost completely relaxed the preparations by $93.1 \pm 2.1 \%$ in the young and $96.5 \pm 3.3 \%$ in the old vessels, respectively (Fig. 1, Table 1).

\section{cAMP mediated vasorelaxation in permeabilized basilar arteries from young and aged mice}

We then tested the effect of cAMP-analogues which specifically activate PKA (6-Bnz-cAMP) and Epac (8-pCPT-

Table 1. Parameters of vasorelaxation induced by UCN-1, Sp-6-Phe-cAMPS ,6- Bnz-cAMP and 8-pCPT-2'-O-Me-cAMP in intact basilar arteries from young and old animals

\begin{tabular}{|c|c|c|c|c|c|}
\hline Age group and type of vasorelaxation & $\begin{array}{c}\text { F SUBMAX }_{\text {SUN }} \\
(\mathrm{mN})\end{array}$ & $\begin{array}{l}\mathrm{F}_{\text {SUBMAX }} \\
\left(\% \mathrm{~F}_{\text {MAX }}\right)\end{array}$ & $\mathrm{pD}_{2}$ & $\begin{array}{c}\mathrm{D}_{\text {MAX }} \\
\left(\% \mathrm{~F}_{\text {SUBMAX }}\right)\end{array}$ & $n$ \\
\hline \multicolumn{6}{|l|}{ Young } \\
\hline UCN-1 & $2.3 \pm 0.9$ & $58.4 \pm 7.8$ & $-8.8 \pm 0.2$ & $93.1 \pm 2.1$ & 5 \\
\hline Sp-6-Phe-cAMPS & $2.8 \pm 0.5$ & $70.9 \pm 9.0$ & n.a. & $12.3 \pm 5.0$ & 4 \\
\hline 6-Bnz-cAMP & $1.58 \pm 0.6$ & $54.8 \pm 9.1$ & n.a. & $26.3 \pm 10.7$ & 3 \\
\hline 8-pCРT-2'-O-Me-cAMP & $1.8 \pm 0.4$ & $63.7 \pm 8.2$ & n.a. & $31.7 \pm 5.5^{\star}$ & 10 \\
\hline 8-pCPT-2'-O-Me-cAMP (no treatment) & $1.2 \pm 0.3$ & $46.8 \pm 4.6$ & n.a. & $58.4 \pm 8.0^{\S}$ & 4 \\
\hline Total & $1.9 \pm 0.2$ & $60.2 \pm 4.1^{\#}$ & - & - & 26 \\
\hline \multicolumn{6}{|l|}{ Old } \\
\hline UCN-1 & $1.5 \pm 0.6$ & $65.0 \pm 10.1$ & $-8.5 \pm 0.1$ & $96.5 \pm 3.3$ & 4 \\
\hline Sp-6-Phe-cAMPS & $2.3 \pm 0.5$ & $84.2 \pm 4.8$ & n.a. & $8.5 \pm 4.7$ & 3 \\
\hline 8-pCРТ-2'-O-Me-cAMP & $3.7 \pm 0.6$ & $83.6 \pm 1.6$ & n.a. & $19.3 \pm 5.5^{\text {n.s. }}$ & 6 \\
\hline 8-pCPT-2'-O-Me-cAMP (no treatment) & $3.6 \pm 0.6$ & $79.4 \pm 4.9$ & n.a. & $31.1 \pm 11.1$ & 4 \\
\hline Total & $2.9 \pm 0.4$ & $78.3 \pm 3.2$ & - & - & 17 \\
\hline
\end{tabular}

${ }^{*} p<0.05$ vs. 8-pCPT-2'-O-Me-cAMP (young, no treatment), ${ }^{\S} p<0.05$ vs. 8-pCPT-2'-O-Me-cAMP (old, no treatment), ${ }^{\text {n.s. }} v s .8$-pCPT-2'O-Me-cAMP (old, no treatment), ${ }^{*} p=0.08$ vs. Total (old), two way ANOVA. $\mathrm{pD}_{2}$, no significant difference between the groups; two way ANOVA. Note: In all experiments except for 8-pCPT-2'-Me-O-cAMP (no treatment), the preparations were preincubated with $10^{-4} \mathrm{~mol} / \mathrm{l}$

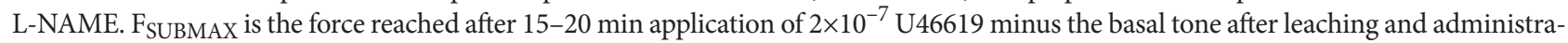
tion of EDTA accepted as $100 \%$. $\mathrm{F}_{\mathrm{MAX}}$, maximal force achieved at $3 \mu \mathrm{mol} / \mathrm{l} \mathrm{U} 46619 ; \mathrm{pD}_{2}$, negative logarithm of molar concentration of an antagonist that would produce a $50 \%$ relaxation; $\mathrm{D}_{\mathrm{MAX}}$, maximal relaxation; $n$, number of experiments (animals); n.a., not applicable; n.s., not significant. 
2'-O-Me-cAMP) in a-toxin permeabilized arteries from both ages (Fig. 2). Application of 6-Bnz-cAMP induced a concentration dependent relaxation of submaximally (pCa 6.21) preconstricted arteries. The $\mathrm{pD}_{2}$ was $6.34 \pm$ 0.37 in young vs. $5.81 \pm 0.11$ in old vessels. Furthermore, an almost complete relaxation of $90.2 \pm 5.9 \%$ was observed in arteries from young vs. $82.0 \pm 7.64 \%$ those from old mice (Fig. 2; Table 2). 8-pCPT-2'-O-Me-cAMP induced also concentration-dependent relaxation with $\mathrm{pD}_{2}$ of $4.43 \pm 0.15$ in young and $4.01 \pm 1.12$ in old arteries and maximal relaxation of $72.1 \pm 7.0 \%$ in young $v s .56 .0 \pm 8.0 \%$ in old (Fig. 2C, D, F; Table 2). The slight decrease in the parameters observed in old arteries could be explained by statistically significant increased submaximal force in this group of preparations $(57.0 \pm 6.1 \%$ young arteries $v s .85 .5$ $\pm 6.6 \%$ in old arteries; $p<0.05 ; n=7-9$; Table 2 ). Furthermore, in old arteries the relaxation induced by activation of PKA was significantly greater than by Epac-activation $(p<0.05)$, whereas there was no significant difference in young arteries.

Aging diminishes the relaxing effect of Epac-analogue in intact basilar arteries and Epac-mediated vasodilation in young vessels was attenuated by inhibition of NO-release

We further tested the efficacy of Epac specific activator 8-pCPT-2'-O-Me-cAMP in intact young and old basilar arteries. In preparations pre-contracted with $2 \times 10^{-7} \mathrm{~mol} / \mathrm{l}$ U46619, cumulative application of 8-pCPT-2'-O-Me-cAMP induced a significant relaxation only at $10^{-4}$ and $3 \times 10^{-4}$ $\mathrm{mol} / \mathrm{l}$. The effect of the compound was overall weak and characterized by non-sigmoidal concentration dependency which differed to the observed effect of UCN-1 in intact or the effect of pCPT-2'-O-Me-cAMP in permeabilized vessels. The maximal relaxation was $58.4 \pm 8.1 \%$ in young arteries and $31.1 \pm 11.1 \%$ in the old vessels $(p<0.05$; Fig. 3, Table 1$)$.
A

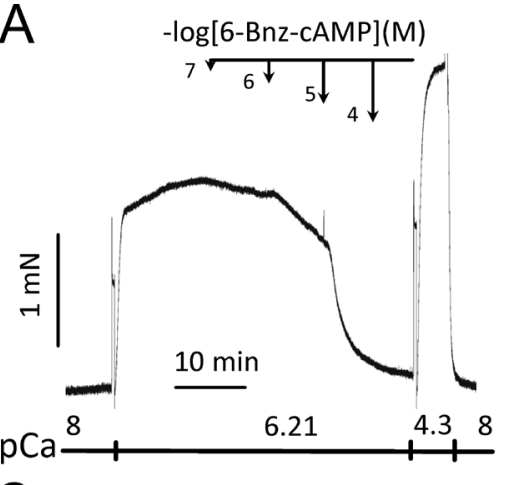

$\mathrm{C}$
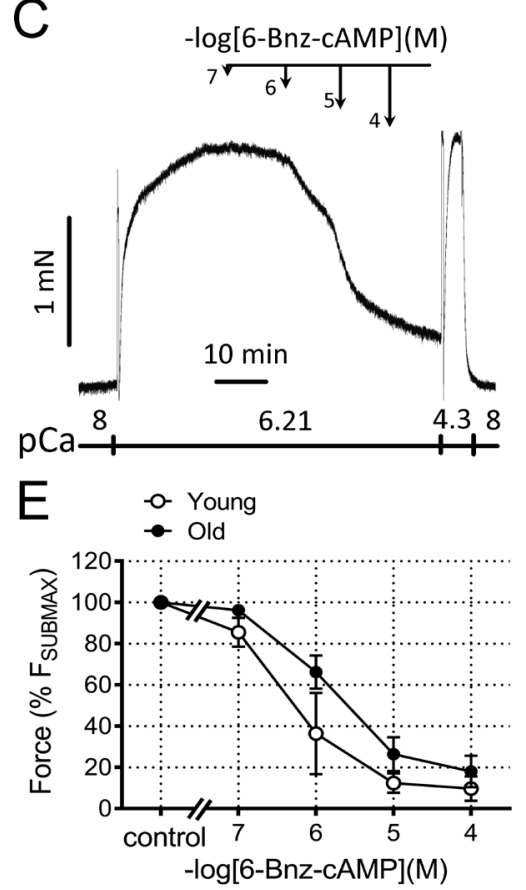

B
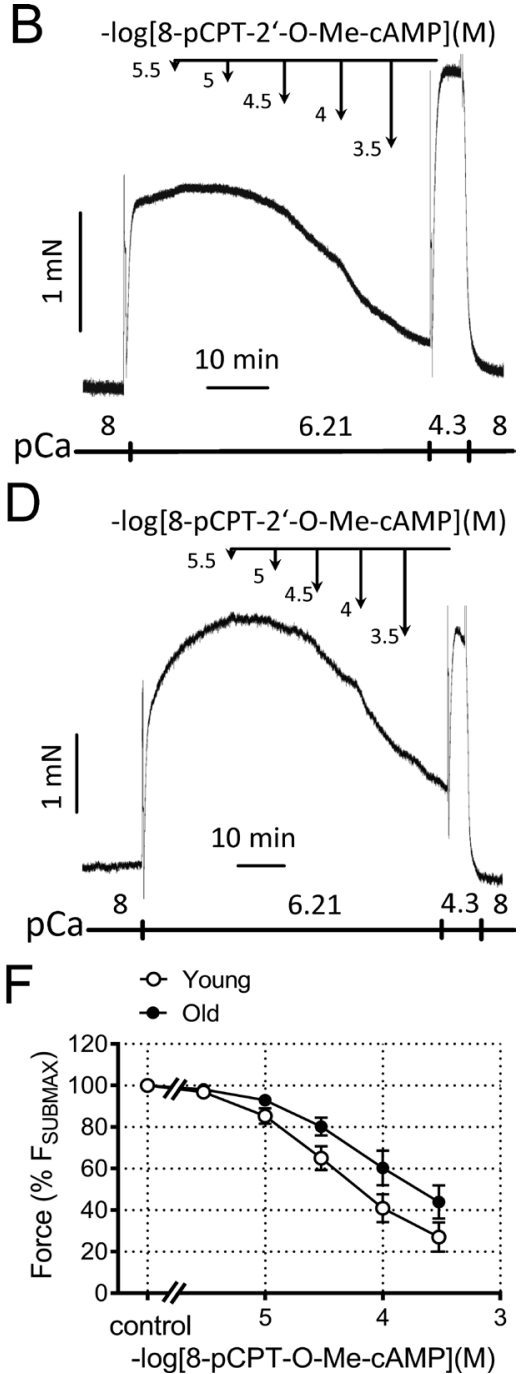

Figure 2. Relaxation induced by 6-Bnz-cAMP and 8-pCPT-2'-O-Me-cAMP in permeabilized murine basilar young $(\mathbf{A}, \mathbf{B})$ and old $(\mathbf{C}, \mathbf{D})$ arteries. Original force recording of the concentration-dependent relaxation in response to PKA activator 6-Bnz-cAMP (A, C) and to Epac activator 8-pCPT-2'-O-Me-cAMP (B, D) of submaximally activated murine basilar arteries ( $n=3$ young and $n=5$ old basilar arteries treated with PKA-ligand and $n=4$ young and $n=6$ old basilar arteries treated with Epac-ligand, respectively). The submaximal contraction was elicited by pCa 6.21. (E, F). Data represented in $\% \mathrm{~F}_{\text {SUBMAX }}$ from steady state force generated by $\sim 15-20$ min stimulation by $\mathrm{pCa} 6.21$, prior to application of cAMP-analogues and accepted as $100 \%$. 
Table 2. Parameters of vasorelaxation induced by 6-Bnz-cAMP and 8-pCPT-2'-O-Me-cAMP in a-toxin permeabilized basilar arteries from young and old animals

\begin{tabular}{|c|c|c|c|c|c|}
\hline Age group and type of vasorelaxation & $\mathrm{F}_{\text {SUBMAX }}(\mathrm{mN})$ & $\mathrm{F}_{\text {SUBMAX }}\left(\% \mathrm{~F}_{\text {MAX }}\right)$ & $\mathrm{pD}_{2}$ & $\mathrm{D}_{\text {MAX }}\left(\% \mathrm{~F}_{\text {SUBMAX }}\right)$ & $n$ \\
\hline \multicolumn{6}{|l|}{ Young } \\
\hline Yo6-Bnz-cAMPung & $1.2 \pm 0.4$ & $44.4 \pm 8.6$ & $-6.3 \pm 0.4$ & $90.2 \pm 5.9$ & 3 \\
\hline 8-pCPT-2'-O-Me-cAMP & $1.4 \pm 0.1$ & $66.5 \pm 4.8$ & $-4.4 \pm 0.2$ & $72.1 \pm 7.0$ & 4 \\
\hline Total & $1.3 \pm 0.2$ & $57.0 \pm 6.0^{*}$ & - & - & 7 \\
\hline \multicolumn{6}{|l|}{ Old } \\
\hline 6-Bnz-cAMP & $2.1 \pm 0.4$ & $88.6 \pm 8.5$ & $-5.8 \pm 0.1$ & $82.0 \pm 7.6^{\S}$ & 6 \\
\hline 8-pCРТ-2'-O-Me-cAMP & $2.2 \pm 0.4$ & $82.4 \pm 11.0$ & $-4.0 \pm 1.1$ & $56.1 \pm 8.0$ & 5 \\
\hline Total & $2.2 \pm 0.3$ & $85.5 \pm 6.6$ & - & - & 11 \\
\hline
\end{tabular}

${ }^{*} p<0.05 v s$. Total F $\mathrm{SUBMAX}_{\text {(old); }}{ }^{\S} p<0.05 v s . \mathrm{D}_{\mathrm{MAX}} 8$-pCPT-2'-O-Me-cAMP (old); $\mathrm{pD}_{2}$ : no significant difference between the groups (all two way ANOVA). Note: F FUBMAX: force at a pCa of 6.21 reached after 15 min stimulation and accepted as $100 \%$. F $_{\text {SUBMAX }}$ in \% is the force normalized to the absolute measured force at $\mathrm{pCa}$ of 4.3 minus the basal tone in relaxation solution $\mathrm{pCa}>8$. For more abbreviations, see Table 1.

Pretreatment with L-NAME before submaximal stimulation with U46619 attenuated maximal relaxation by pCPT-2'-OMe-cAMP to $31.7 \pm 5.5 \%$ in the young and $18.3 \pm 5.5 \%$ in the old vessels $(p<0.05$; Fig. 3 , Table 1$)$. This suggests that at least a part of the observed relaxation could be due to NO release from endothelium or perivascular nerves.

\section{PKA activators are virtually ineffective in intact basilar arteries}

Since relaxation by the Epac activator was achieved only at very high concentrations we also tested the relaxing effect of specific PKA activation in intact basilar arteries from young and old animals in the next experiments. For this purpose, two specific PKA activators 6-Bnz-cAMP or Sp-6Phe-cAMPS were used. These cAMP analogs have a 3-fold (6-Bnz-cAMP) or 2-fold (Sp-6-Phe-cAMPS) higher binding affinity for PKA and only at very high concentration act as partial agonists of Epac (Christensen et al. 2003). According to the manufacturer, Sp-6-Phe-cAMPS is also more membranepermeable than 6-Bnz-cAMP. Since the Epac relaxing effect seems to be partially mediated by NO release, next experiments were performed in continuous presence of $10^{-4} \mathrm{~mol} / \mathrm{l}$ L-NAME. However, in young basilar arteries the effect of 6-Bnz-cAMP on vascular tone was very weak and even at the maximum concentration of $10^{-4} \mathrm{~mol} / \mathrm{l}, 6-\mathrm{Bnz}-\mathrm{cAMP}$ relaxed the preparation by only $\sim 20 \%$ ( $n=3$; not shown). Application of the same concentrations of "highly permeable" PKA activator Sp-6-Phe-cAMPS did not relax preparations from both age groups. By increasing the compound concentration to $300 \mu \mathrm{mol} / \mathrm{l}$, maximal relaxation induced by Sp-6-Phe-cAMPS was only $12.3 \pm 5.0 \%$ in young and $8.5 \pm 4.7 \%$ in old arteries (Fig. 4, Table 1). These values were similar to the decline of the submaximal force measured with time (time matched
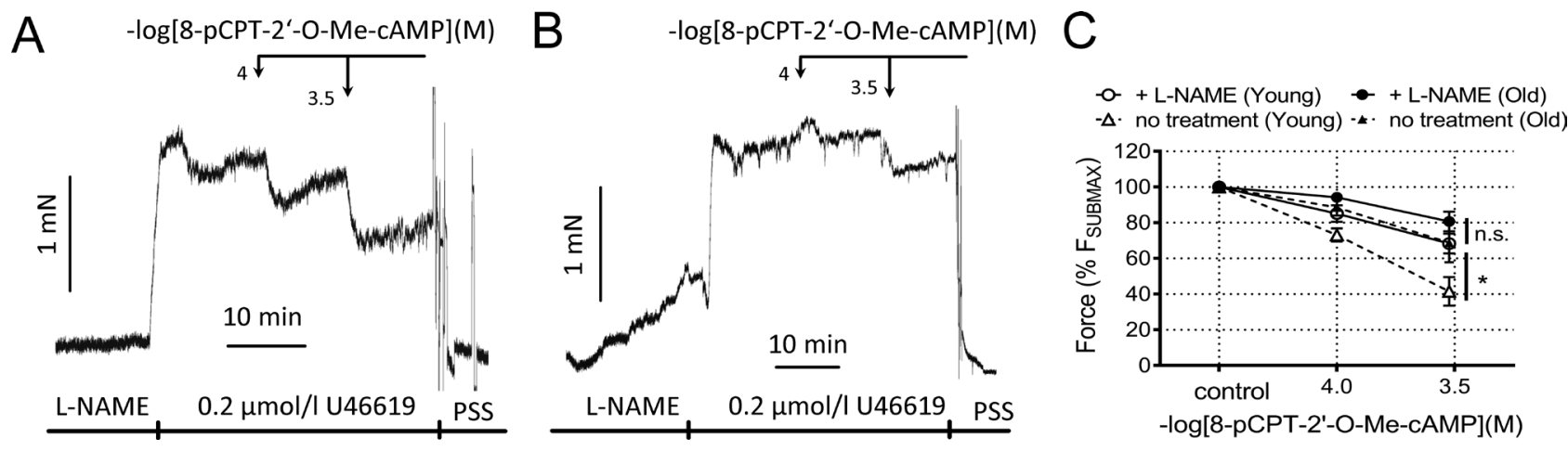

Figure 3. NO dependence of relaxing effect of Epac activator, 8-pCPT-2'-O-Me-cAMP on intact basilar arteries. Original record representing the concentration-dependent effect of 8-pCPT-2'-O-Me cAMP in young (A) and old (B) basilar arteries ( $n=10$ (young basilar arteries treated with $100 \mu \mathrm{mol} / \mathrm{l} \mathrm{L-NAME),} n=4$ (young vessels without treatment), $n=6$ (old basilar arteries treated with $100 \mu \mathrm{mol} / \mathrm{l}$ L-NAME), $n=4$ (old vessels without treatment). C. Summary of results. Data normalized to F SUBMAX $^{*} p<0.05$, two-way ANOVA. 

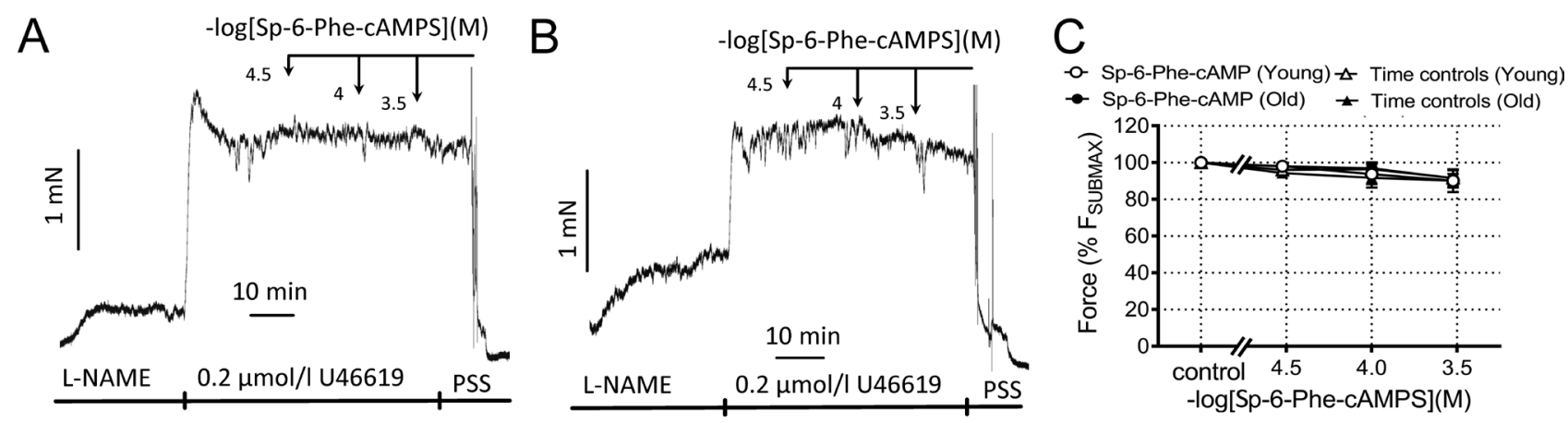

Figure 4. Effect of PKA-activator Sp-6-Phe-cAMPS on intact basilar arteries. Original force tracings representing the effect of Sp-6-PhecAMPS in young (A) and old (B) basilar arteries pretreated with $100 \mu \mathrm{mol} / \mathrm{l} \mathrm{L}-\mathrm{NAME}$ and stimulated submaximally with $2 \times 10^{-7} \mathrm{~mol} / \mathrm{l}$ U46619. C. Summary of results from $n=4$ young and $n=3$ old arteries $v$ s. $n=4$ young and $n=3$ old arteries used as time matched controls (no Sp-6-Phe-cAMPS treatment denoted as "Time controls"). Data represented in \% FSUBMAX.

controls; Fig. 4), suggesting that in intact basilar arteries the specific PKA activating compounds are virtually ineffective likely due to their lower membrane permeability.

\section{Discussion}

This study presents data showing that UCN-1 relaxes basilar arteries from young and aged mice with equal $\mathrm{pD}_{2}$. Furthermore, in permeabilized arteries cAMP-analogues which specifically activate Epac or PKA relaxed young and old basilar arteries similarly suggesting that ageing does not affect cAMP-dependent basilar artery relaxation in mice. The effect of Epac-ligands on intact basilar arteries was attenuated by inhibition of NO-liberation supporting the view that a part of the Epac-related relaxation is mediated by NO release. In aged basilar arteries this relaxation was diminished and less NOdependent suggesting that aging impairs Epac-dependent NOS activation in endothelial cells. In addition, our study also shows that cAMP-ligands which specifically activate PKA are ineffective in intact arteries supporting the view for a low permeability of these compounds under intact conditions.

\section{Role of Epac in the regulation of vascular tone}

The discovery of Epac two decades ago broke the dogma that all effects of cAMP could be attributed to the activation of only PKA and CNGCs. In a series of publications it has been shown that activation of Epac is a central mechanism involved in cardiac performance, inflammation, endothelial synthesis and release as well as blood brain barrier protection (Parnell et al. 2015; Lezoualc'h et al. 2016; ChrzanowskaWodnicka 2017; Ramos and Antonetti 2017). Furthermore, the crucial role of Epac2/Rap1 in insulin secretion as well as the role of its downregulation in development of type II diabetes has been also thoroughly investigated (Tengholm and Gylfe 2017). In addition, Epac seems to act also as regulator of vascular tone and contractility. Some early in vitro studies revealed that specific Epac-ligands are able to relax rat aortic rings (Sukhanova et al. 2006). This first report pointed out the importance of Epac-proteins in vascular system and encouraged different groups to subject this pathway to detailed investigation. Epac has been shown to regulate vascular tone in different species and vascular beds and the underlying mechanisms have been attributed to effects on $\mathrm{Ca}^{2+}$ mobilization and $\mathrm{K}^{+}$-channel conductance (Purves et al. 2009; Roberts et al. 2013; Stott et al. 2016). Furthermore, cAMP formed in response to a $\beta$-adrenoceptor agonist and prostaglandin-I2 has been shown to inactivate Rho/ROK via the Epac/Rap1 system resulting in vascular smooth muscle $\mathrm{Ca}^{2+}$-desensitization (Zieba et al. 2011). In line with these findings we can show that Epac-activator relaxes permeabilized basilar arteries at constant intracellular $\mathrm{Ca}^{2+}$-concentration. In addition, in airway smooth muscle cells activation of another small G-protein member Rac1 has been shown to parallel Epac1-mediated cAMP activation (Roscioni et al. 2011). All of these findings led to the generation of genetically engineered animal models to delineate the significance of Epac for the future. In vivo Rap1 knock out increases vascular tone as well as arterial pressure (Lakshmikanthan et al. 2014) and is associated with micro bleeding which mechanistically relate to impaired endothelial permeability (Chrzanowska-Wodnicka et al. 2005); reviewed in Ramos and Antonetti (2017).

\section{Dual nature of the effect of Epac-ligands in basilar arteries: effects of aging on direct smooth muscle relaxation and those mediated by activation of endothelial NO-release}

Our study is reporting significant relaxation activity of the Epac-ligands in brain vascular system and especially on basilar artery, a large conducting vessel playing crucial role 
in blood supply for so called posterior brain circulation (Markus et al. 2013). Here we also report that aging blunts the relaxing ability of the Epac-ligands which is in the line with previous reports showing a diminution of Epac-effect at pathological conditions (reviewed in Metrich et al. 2010). Our study also supports the view that in murine basilar arteries relaxation related to Epac is partially mediated through NO-release from vascular endothelium. Here we show that in young basilar arteries inhibition of NO-formation by L-NAME attenuates by $\sim 2$-fold the relaxation efficiency of 8-pCPT-2'-O-Me-cAMP (58.4 $\pm 8.0 \%$ in untreated basilar arteries vs. $31.7 \pm 5.5 \%$ in in the vessels treated with $\mathrm{L}$ NAME; Fig. 3, Table 1). This could be mediated by Rap1, an Epac1 effector, that has been shown to promote NO-release from the vascular endothelium (reviewed in ChrzanowskaWodnicka 2017). By contrast, in aged basilar arteries Epac relaxation was 2 -fold attenuated and less sensitive to $\mathrm{NO}$ inhibition $(31.1 \pm 11$ in absence $v s 19.3 \pm 5.5 \%$ in presence of L-NAME, Fig. 3, Table 1), suggesting that old age diminishes the endothelial part of Epac relaxing effect in brain vessels. Pharmacological studies revealed that in brain arteries NO is released mainly from non-endothelial sources. It has been shown that in large conducting brain arteries $\sim 60 \%$ of the generated NO originated from perivascular nerves and only $\sim 40 \%$ from non-neuronal tissues, mainly the endothelium (Okamura et al. 2002), suggesting that pan-NOS inhibition through L-NAME might also inhibit the NO-liberation from perivascular nerves. This stoichiometry that likely also applies to humans is typical for young age and does not apply to old murine basilar arteries (Lubomirov et al. 2017). Recently we have shown that senescence silences neuronal
NO liberation (Lubomirov et al. 2017). However, we cannot exclude that at least part of the Epac relaxation in young basilar arteries could be mediated via Epac1/Rap1 NOliberation from perivascular nerves. Our study is limited in this regard as for the delineation of the exact stoichiometry of endothelial/neuronal NO liberation further investigations will be required.

Alternatively, diminution of Epac efficacy could be also ascribed to upregulation of RhoA-G-Protein/Rho-Kinase (Rho/ROK) pathway leading to the hypercontractile state of the smooth muscle cells. Recently we reported that in old-aged basilar arteries the Thr853-phosphorylation of the regulatory subunit of MLCP, MYPT1 is elevated compared to vessels obtained from young mature animals (Lubomirov et al. 2017). This phospho-site has been shown to be solely phosphorylated by ROK and could be used as marker for monitoring ROK-activity (Khasnis et al. 2014). The upregulation of Rho/ROK pathway by itself would promote augmented $\mathrm{Ca}^{2+-}$ sensitivity via a reduction in MLCP-activity (Puetz et al. 2009) or change in actincytoskeleton dynamics (Walsh and Cole 2013) and thus attenuate the relaxing effect of Epac-ligands. In this regard a large body of evidence revealed the importance of redox regulation for Rho/ROK signaling and basal Rho/ROK activity (Jin et al. 2004; Jernigan et al. 2008) and that aging accelerates reactive oxygen species (ROS) production in endothelium, neurons and glia cells which in turn impedes NO/cGMP-mediated relaxation (Park et al. 2007). In this context cerebrovascular aging has been shown to be associated with a loss of antioxidant capacity and augmented peroxynitrite formation (van der Loo et al. 2000; Tumer et

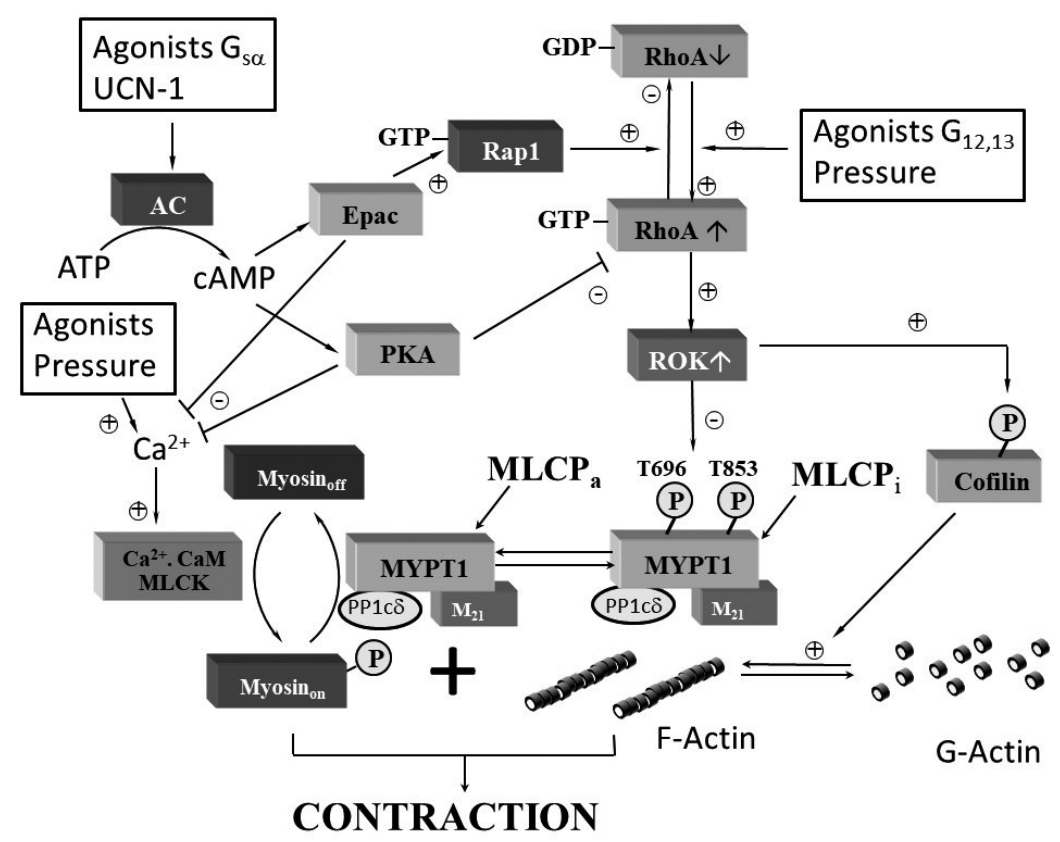

Figure 5. Schematic cartoon representing the putative mechanisms of RhoA/ROK and cAMPmediated $\mathrm{Ca}^{2+}$-sensitization/desensitization in the cerebrovascular smooth muscle cells. AC, adenylyl cyclase; UCN-1, urocortin 1; PKA, protein kinase A; Epac, exchange-protein-directlyactivated by cAMP; MLCP, myosin light chain phosphatase; MLCP $\mathrm{a}_{\mathrm{a}}$ and MLCP $_{\mathrm{i}}$, active and inactive MLCP; $\mathrm{Ca}^{2+}$.MLCK, calcium/calmodulinactivated myosin light chain kinase; MYPT1, 115 $\mathrm{kDa}$ regulatory (myosin phosphatase targeting) subunit ; PP1c $\delta$, catalytic subunit of MLCP; $\mathrm{M}_{21}, 21 \mathrm{kDa}$ subunit of MLCP; T696 and T853 phosphorylation sites of MYPT1; Rap1, small GTPase Ras-proximate-1 or Ras-related protein 1; RhoA, small GTPase Ras homolog gene family; member A; ROK, RhoA kinase. Explanations are given in the text in "Introduction". Numbering of the phosphorylation sites is given in human sequence. 
al. 2014). In a recent study using a similar model of aging, we have shown that ROS inhibition restores the normocontractile phenotype and NO-sensitivity of the smooth muscle cells in aged murine basilar arteries (Lubomirov et al. 2017). All these findings greatly support the notion that increased smooth muscle contractility would be possibly one of the underlying mechanisms of diminution of the relaxing effect of Epac-ligands in old basilar arteries. In line with this we also observed augmented submaximal $\mathrm{Ca}^{2+}$-contractility of permeabilized aged basilar arteries (Table 2). Interestingly, in the permeabilized young arteries Epac-activator was able to induce relaxation with nearly equal $D_{\max }$ compared to PKA, whereas in aged vessels this parameter compared was significantly attenuated (Table 2). This strongly suggests that impairment of Epac-related relaxation is in the first line affected by aging whereas PKA related relaxation is less sensitive. Schematic presentation of the putative mechanisms involved in PKA/Epac sensitization in cerebral smooth muscle is represented on Figure 5.

\section{Perspectives}

Given that intact basilar arteries are permeable for Epac but not for PKA analogues there is a good chance allowing therapeutic differentiation between both pathways with the option for exclusive activation of Epac in brain circulatory system. It would be expected that Epac ligands will support cerebral perfusion through mild vasorelaxation, relieving the inflammatory component, and stabilizing bloodbrain barrier function via predominantly endothelial and smooth muscle-mediated relaxation effects. Moreover, it would be also expected that the moderate relaxing effect of Epac-ligands will not lead to hyporesistance of brain vessels due to complete loss of the myogenic tone (typical for the effects of strongly relaxing substances such as $\mathrm{NO}$-donors and PDE-activators), avoiding exposure of brain to overperfusion and endangering of important brain areas. All these notions strongly encourage use of Epac-ligands for future in vivo pharmacological studies at least in animal models.

Acknowledgements. Funding was provided by the German Research Association (DFG, SFB612) and the Medical Faculty of University of Cologne (Koeln Fortune) to G.P. Authors gratefully acknowledge the expert technical assistance of Doris Metzler.

Author contribution. Idea and design of experiments: J.W., L.T.L., and G.P. Manuscript writing: J.W., L.T.L., O.G., J.H. and G.P. Wire myography: J.W. and L.T.L. Statistic evaluation and comparison: J.W. and G.P.

Conflict of interests. Authors declare no conflict of interests.

\section{References}

Alenkvist I, Gandasi NR, Barg S, Tengholm A (2017): Recruitment of Epac2A to insulin granule docking sites regulates priming for exocytosis. Diabetes 66, 2610-2622 https://doi.org/10.2337/db17-0050

Brescia M, Zaccolo M (2016): Modulation of compartmentalised cyclic nucleotide signalling via local inhibition of phosphodiesterase activity. Int. J. Mol. Sci. 17, 10 https://doi.org/10.3390/ijms17101672

Chen ZW, Huang Y, Yang Q, Li X, Wei W, He GW (2005): Urocortininduced relaxation in the human internal mammary artery. Cardiovasc. Res. 65, 913-920

https://doi.org/10.1016/j.cardiores.2004.11.018

Christensen AE, Selheim F, de Rooij J, Dremier S, Schwede F, Dao KK, Martinez A, Maenhaut C, Bos JL, Genieser HG, Døskeland SO (2003): cAMP analog mapping of Epac1 and cAMP kinase. Discriminating analogs demonstrate that Epac and cAMP kinase act synergistically to promote PC-12 cell neurite extension. J. Biol. Chem. 278, 35394-402 https://doi.org/10.1074/jbc.M302179200

Chrzanowska-Wodnicka M (2017): Rap1 in endothelial biology. Curr. Opin. Hematol. 24, 248-255 https://doi.org/10.1097/MOH.0000000000000332

Emeto TI, Moxon JV, Rush C, Woodward L, Golledge J (2011): Relevance of urocortins to cardiovascular disease. J. Mol. Cell Cardiol. 51, 299-307 https://doi.org/10.1016/j.yjmcc.2011.06.002

Etter EF, Eto M, Wardle RL, Brautigan DL, Murphy RA (2001): Activation of myosin light chain phosphatase in intact arterial smooth muscle during nitric oxide-induced relaxation. J. Biol. Chem. 276, 34681-34685 https://doi.org/10.1074/jbc.M104737200

Feng J, Ito M, Ichikawa K, Isaka N, Nishikawa M, Hartshorne DJ, Nakano T (1999a): Inhibitory phosphorylation site for Rhoassociated kinase on smooth muscle myosin phosphatase. J. Biol. Chem. 274, 37385-37390 https://doi.org/10.1074/jbc.274.52.37385

Feng J, Ito M, Nishikawa M, Okinaka T, Isaka N, Hartshorne DJ, Nakano T (1999b): Dephosphorylation of distinct sites on the $20 \mathrm{kDa}$ myosin light chain by smooth muscle myosin phosphatase. FEBS Lett. 448, 101-104 https://doi.org/10.1016/S0014-5793(99)00337-3

Fukuhara S, Sakurai A, Sano H, Yamagishi A, Somekawa S, Takakura N, Saito Y, Kangawa K, Mochizuki N (2005): Cyclic AMP potentiates vascular endothelial cadherin-mediated cell-cell contact to enhance endothelial barrier function through an Epac-Rap1 signaling pathway. Mol. Cell Biol. 25, 136-146 https://doi.org/10.1128/MCB.25.1.136-146.2005

Huang Y, Chan FL, Lau CW, Chan YC, Tsang SY, Chan FL (2002): Urocortin-induced endothelium-dependent relaxation of rat coronary artery: role of nitric oxide and $\mathrm{K}+$ channels. Br. J. Pharmacol. 135, 1467-1476 https://doi.org/10.1038/sj.bjp.0704587

Iadecola C, Park L, Capone C (2009): Threats to the mind: aging, amyloid, and hypertension. Stroke 40 (Suppl. 3), S40-44 https://doi.org/10.1161/STROKEAHA.108.533638 
Jernigan NL, Walker BR, Resta TC (2008): Reactive oxygen species mediate RhoA/Rho kinase-induced $\mathrm{Ca} 2+$ sensitization in pulmonary vascular smooth muscle following chronic hypoxia. Am. J. Physiol. Lung Cell Mol. Physiol. 295, L515-529 https://doi.org/10.1152/ajplung.00355.2007

Jin L, Ying Z, Webb RC (2004): Activation of Rho/Rho kinase signaling pathway by reactive oxygen species in rat aorta. Am. J. Physiol. Heart Circ. Physiol. 287, H1495-1500 https://doi.org/10.1152/ajpheart.01006.2003

Khasnis M, Nakatomi A, Gumpper K, Eto M (2014): Reconstituted human myosin light chain phosphatase reveals distinct roles of two inhibitory phosphorylation sites of the regulatory subunit, MYPT1. Biochemistry 53, 2701-2709 https://doi.org/10.1021/bi5001728

Khromov A, Choudhury N, Stevenson AS, Somlyo AV, Eto M (2009): Phosphorylation-dependent autoinhibition of myosin light chain phosphatase accounts for $\mathrm{Ca} 2+$ sensitization force of smooth muscle contraction. J. Biol. Chem. 284, 21569-21579 https://doi.org/10.1074/jbc.M109.019729

Kitazawa T, Eto M, Woodsome TP, Khalequzzaman M (2003): Phosphorylation of the myosin phosphatase targeting subunit and CPI-17 during Ca2+ sensitization in rabbit smooth muscle. J. Physiol. 546, 879-889 https://doi.org/10.1113/jphysiol.2002.029306

Kooistra MR, Corada M, Dejana E, Bos JL (2005): Epac1 regulates integrity of endothelial cell junctions through VE-cadherin. FEBS Lett. 579, 4966-4972 https://doi.org/10.1016/j.febslet.2005.07.080

Lezoualc'h F, Fazal L, Laudette M, Conte C (2016): Cyclic AMP Sensor EPAC Proteins and Their Role in Cardiovascular Function and Disease. Circ. Res. 118, 881-897 https://doi.org/10.1161/CIRCRESAHA.115.306529

Lubomirov LT, Papadopoulos S, Putz S, Welter J, Klöckener T, Weckmüller K, Ardestani MA, Filipova D, Metzler D, Metzner $\mathrm{H}$, et al. (2017): Aging-related alterations in eNOS and nNOS responsiveness and smooth muscle reactivity of murine basilar arteries are modulated by apocynin and phosphorylation of myosin phosphatase targeting subunit-1. J. Cereb. Blood Flow. Metab. 37, 1014-1029 https://doi.org/10.1177/0271678X16649402

Lubomirov LT, Papadopoulos S, Filipova D, Baransi S, Todorović D, Lake P, Metzler D, Hilsdorf S, Schubert R, Schroeter MM, Pfitzer G (2018): The involvement of phosphorylation of myosin phosphatase targeting subunit 1 (MYPT1) and MYPT1 isoform expression in NO/cGMP mediated differential vasoregulation of cerebral arteries compared to systemic arteries. Acta Physiol. 224, e13079 https://doi.org/10.1111/apha.13079

Markus HS, van der Worp HB, Rothwell PM (2013): Posterior circulation ischaemic stroke and transient ischaemic attack: diagnosis, investigation, and secondary prevention. Lancet Neurol. 12, 989-998 https://doi.org/10.1016/S1474-4422(13)70211-4

Metrich M, Berthouze M, Morel E, Crozatier B, Gomez AM, Lezoualc'h F (2010): Role of the cAMP-binding protein Epac in cardiovascular physiology and pathophysiology. Pflugers Arch. 459, 535-546 https://doi.org/10.1007/s00424-009-0747-y
Mufti RE, Brett SE, Tran CH, Abd El-Rahman R, Anfinogenova Y, El-Yazbi A, Cole WC, Jones PP, Chen SR, Welsh DG (2010): Intravascular pressure augments cerebral arterial constriction by inducing voltage-insensitive Ca2+ waves. J. Physiol. 588, 3983-4005 https://doi.org/10.1113/jphysiol.2010.193300

Mulvany MJ, Halpern W (1977): Contractile properties of small arterial resistance vessels in spontaneously hypertensive and normotensive rats. Circ. Res. 41, 19-26 https://doi.org/10.1161/01.RES.41.1.19

Okamura T, Ayajiki K, Fujioka H, Shinozaki K, Toda N (2002): Neurogenic cerebral vasodilation mediated by nitric oxide. Jpn. J. Pharmacol. 88, 32-38 https://doi.org/10.1254/jjp.88.32

Park L, Anrather J, Girouard H, Zhou P, Iadecola C (2007): Nox2-derived reactive oxygen species mediate neurovascular dysregulation in the aging mouse brain. J. Cereb. Blood Flow. Metab. 27, 1908-1918 https://doi.org/10.1038/sj.jcbfm.9600491

Parnell E, Palmer TM, Yarwood SJ (2015): The future of EPACtargeted therapies: agonism versus antagonism. Trends Pharmacol. Sci. 36, 203-214 https://doi.org/10.1016/j.tips.2015.02.003

Pfitzer G (2001): Invited review: regulation of myosin phosphorylation in smooth muscle. J. Appl. Physiol. 91, 497-503 https://doi.org/10.1152/jappl.2001.91.1.497

Pfitzer G, Hofmann F, DiSalvo J, Ruegg JC (1984): cGMP and cAMP inhibit tension development in skinned coronary arteries. Pflugers Arch. 401, 277-280 https://doi.org/10.1007/BF00582596

Pfitzer G, Ruegg JC, Zimmer M, Hofmann F (1985) Relaxation of skinned coronary arteries depends on the relative concentrations of $\mathrm{Ca} 2+$, calmodulin and active cAMP-dependent protein kinase. Pflugers Arch. 405, 70-76 https://doi.org/10.1007/BF00591100

Poppinga WJ, Munoz-Llancao P, Gonzalez-Billault C, Schmidt M (2014): A-kinase anchoring proteins: cAMP compartmentalization in neurodegenerative and obstructive pulmonary diseases. Br. J. Pharmacol. 171, 5603-5623 https://doi.org/10.1111/bph.12882

Puetz S, Lubomirov LT, Pfitzer G (2009): Regulation of smooth muscle contraction by small GTPases. Physiology 24, 342-356 https://doi.org/10.1152/physiol.00023.2009

Ramos CJ, Antonetti DA (2017): The role of small GTPases and EPAC-Rap signaling in the regulation of the blood-brain and blood-retinal barriers. Tissue Barriers 5, e1339768 https://doi.org/10.1080/21688370.2017.1339768

Somlyo AP, Somlyo AV (2003): Ca2+ sensitivity of smooth muscle and nonmuscle myosin II: modulated by G proteins, kinases, and myosin phosphatase. Physiol. Rev. 83, 1325-1358 https://doi.org/10.1152/physrev.00023.2003

Tumer N, Toklu HZ, Muller-Delp JM, Oktay S, Ghosh P, Strang K, Delp MD, Scarpace PJ (2014): The effects of aging on the functional and structural properties of the rat basilar artery. Physiol. Rep. 2, 6

https://doi.org/10.14814/phy2.12031

van der Loo B, Labugger R, Skepper JN, Bachschmid M, Kilo J, Powell JM, Palacios-Callender M, Erusalimsky JD, 
Quaschning T, Malinski T (2000): Enhanced peroxynitrite formation is associated with vascular aging. J. Exp. Med. 192, 1731-1744

https://doi.org/10.1084/jem.192.12.1731

Vaughan J, Donaldson C, Bittencourt J, Perrin MH, Lewis K, Sutton S, Chan R, Turnbull AV, Lovejoy D, Rivier C, et al. (1995): Urocortin, a mammalian neuropeptide related to fish urotensin I and to corticotropin-releasing factor. Nature 378, 287-292 https://doi.org/10.1038/378287a0

Walsh MP, Cole WC (2013): The role of actin filament dynamics in the myogenic response of cerebral resistance arteries. J. Cereb. Blood Flow. Metab. 33, 1-12 https://doi.org/10.1038/jcbfm.2012.144

Wirth A, Schroeter M, Kock-Hauser C, Manser E, Chalovich JM, De Lanerolle P, Pfitzer G. (2003): Inhibition of contraction and myosin light chain phosphorylation in guinea-pig smooth muscle by p21-activated kinase 1. J. Physiol. 549, 489-500 https://doi.org/10.1113/jphysiol.2002.033167

Yang T, Sun Y, Lu Z, Leak RK, Zhang F (2017): The impact of cerebrovascular aging on vascular cognitive impairment and dementia. Ageing Res. Rev. 34, 15-29 https://doi.org/10.1016/j.arr.2016.09.007

Zieba BJ, Artamonov MV, Jin L, Momotani K, Ho R, Franke AS, Neppl RL, Stevenson AS, Khromov AS, Chrzanowska-Wodnicka M, Somlyo AV (2011): The cAMP-responsive Rap1 guanine nucleotide exchange factor, Epac, induces smooth muscle relaxation by down-regulation of RhoA activity. J. Biol. Chem. 286, 16681-16692 https://doi.org/10.1074/jbc.M110.205062

Received: August 29, 2019

Final version accepted: November 18, 2019 